\title{
DOUBLE LEFT RENAL VEIN- A RARE ANOMALY
}

Rupshikha Dutta1, Manash Jyoti Phukon².

1. Associate Professor, Department of Anatomy, Prathima Institute of Medical Sciences.

2. Professor, Department of Anatomy, Prathima Institute of Medical Sciences.

\section{CORRESPONDING AUTHOR:}

Dr Manash Jyoti Phukon,

Professor of Anatomy,

Prathima Institute of Medical Sciences,

Nagnoor Road, Karimnagar, Pin505417,

Andhra Pradesh, India.

Email-manash06@yahoo.co.in

\section{HOW TO CITE THIS ARTICLE:}

Rupshikha Dutta1, Manash Jyoti Phukon. "Double Left Renal Vein- A Rare Anomaly". Journal of Evolution of Medical and Dental Sciences 2013; Vol2, Issue 23, June 10; Page: 4238-4243.

ABSTRACT: During routine dissection for the students from 2006 - 2011, an adult male cadaver was observed to have double left renal vein. Both the veins were opening into the inferior vena cava. One is preaortic and the other is post aortic channel forming a ring around the aorta called circumaortic, or persistent renal collar.

Double left renal vein is a rare developmental anomaly, but carries immense surgical importance. Injury to the postaortic channel during surgery may lead to severe haemorrhage.

So profound knowledge is necessary for this variation. The embryological aspect and the clinical importance of the case are discussed here.

KEY WORDS: Double left renal vein, retro-aortic vein, renal collar, abdominal aortic aneurysm.

INTRODUCTION: Congenital anomalies of Inferior Vena Cava (IVC) and its tributaries are known to anatomists since 1793 (1). It is commonly recognized in symptomatic patients. The embryogenesis of the IVC is a complex process involving the formation of several anastomoses between three paired embryonic veins. It results into numerous variations in the basic plan of venous return from abdomen and lower limbs (2).

The right and left renal vein drains blood into inferior vena cava from each kidney. The left renal vein is longer than the right renal vein and drains blood from the left gonad and left suprarenal gland as well. The left renal vein crosses the front of abdominal aorta below the origin of superior mesenteric artery (3).

Here a case of double left renal vein and its embryological basis is discussed.

MATERIALS AND METHODS: In the years from 2006-2011, properly embalmed 30 cadavers (25 males, 5 females) were dissected for demonstration to students of first MBBS . During the course , a rare variation known as "Double left renal vein" was observed in an adult male. 


\section{CASE REPORT}

OBSERVATION: During dissection of the abdomen, an adult male cadaver presented double left renal vein (DLRV). Both were opening into inferior vena cava, one pre aortic and other post aortic. The latter being about $2 \mathrm{~cm}$ inferior to the former. Thus, a circumaortic ring was observed. The left supra renal vein joined the pre aortic, while the left gonadal vein drained into post aortic channel. Multiple veins draining the left kidney were observed to join the ring (Fig-1,2). The right renal vein was observed to be normal. Each kidney was supplied by a single renal artery.

The case presented no other anomaly.

DISCUSSION: Normally the renal veins lie anterior to the renal arteries and open into the Inferior vena cava almost at right angles. The left renal vein is about three times longer $(7.5 \mathrm{~cm})$ than the right $(2.5 \mathrm{~cm})$ one $(3,4)$.

In the embryo, initially, the cardinal veins form the main venous drainage. During the $5^{\text {th }}$ to $7^{\text {th }}$ week, paired longitudinal channels, the subcardinal and the supracardinal veins appear by the sides of the posterior cardinal veins. Then, a plexiform venous collar develops, encircling the dorsal aorta and drains the permanent kidney. This circumaortic venous collar or, the renal collar (Fig- 3,4$)$ is formed by -

i) Pre-aortic anastomosis between the subcardinal veins,

ii) Anastomosis between the supracardinal and subcardinal vein,

iii) Anastomosis between the supracardinal vein and azygos venous line,

iv) Anastomosis between the azygous venous lines and the subcentral veins,

v) Post-aortic anastomosis of the two subcentral veins,

Normally, the retro aortic components atrophy and the preaortic anastomosis persist and develop into left renal vein which passes in front of the aorta and renal arteries to open into the IVC. When the preaortic anastomosis regress the left renal vein is retro aortic. The right subcardinal vein is directly incorporated into IVC forming its renal segment $(5,6,7)$.

Complicated sequences of venous development may result in abnormal connections. The persistence of 'renal collar' gives rise to double left renal veins, preaortic and post aortic both draining into the IVC(6).

The term 'renal collar' in embryo was designated by Huntingdon and McClure in 1920 (8).

Double left renal vein is a rare developmental anomaly. Few literatures are available reporting such cases $(9$,

The Incidence accounts to be $1.5 \%$ to $8.7 \%$ (10).

Davis and Lundbery reported in 270 autopsies a retroaortic left renal vein in $1.8 \%$ and circumaortic renal collar in 1.5\% (11)

Reis and Esentha reported 2.4\% incidence of venous collar (12)

Brener in 1974, had mentioned two patients with DLRV associated with abdominal aortic aneurysm in a series of 31 major venous anomalies of the renal vein and the inferior vena cava (13). Brener and Nonami emphasized the importance of retroaortic channel indicating the possibility of severe bleeding in this type of patients (14).

Riichiro Toda reported a patient, 72 year old man presenting DLRV associated with abdominal aortic aneurysm (15).

In 2002, M. Jafarpour et al from Mashhad University Iran studied 32 male cadavers and found $6.5 \%$ of double left renal vein (16). 


\section{CASE REPORT}

However, Hemlatha K. et al in 2008, reported a very low incidence of renal collar, i.e. only $0.3 \%$ in their study (17).

In 2010, Sangeetha $\mathrm{K}$ et al observed a male case having a circumaortic renal collar in a study of 20 cadavers (18).

In the present study, we have encountered only one male case with a persistent renal collar out of 30 cadavers, accounting to incidence of $3.33 \%$.

Variation of left renal vein is important to surgeons. As this vein is longer,

i) The left kidney is the preferred sight of life donor nephrectomy,

ii) Leino - renal shunt is done in portal hypertension,

iii) Because of its close proximity to aorta during surgery for abdominal aortic aneurysm, the left renal vein is usually ligated to the right of the draining gonadal and suprarenal vein . This usually provides adequate collateral venous drainage. The right renal vein has no significant collateral drainage.

Contrast-enhanced CT and MRI are enough to give valuable information about venous anomalies and abdominal aortic aneurysm (19).

CONCLUSION: The variations in the basic plan of venous return from the abdomen and lower extremity have significant clinical implications. Profound knowledge of the variations are important to correct cross-sectional images, to avoid erroneous diagnosis of retroperitoneal and mediastinal masses or, adenopathy. This alerts surgeons and angiographers of potential sources of complication preoperatively.

The case of 'persistence renal collar' is a challenge in the surgical field. Especially, injury to the retroaortic channel may lead to severe haemorrhage. Hence, proper knowledge of these variations helps to reduce the morbidity and mortality of the patients.

ACKNOWLEDGEMENT: The authors express gratitude to D. Sushant Reddy and Dr. Sd. Nazir for their help during dissection and preparation of the manuscript.

\section{REFERENCES:}

1. Abernethy J Account of two instances of uncommon formation in the viscera of the human body. Philos trans R Soc. 1793; 83: 59-66.

2. Bass JE, Redwine MD, Krammer LA, Huynh PT, Harris JH. Spectrum of Congenital Anomalies of the Inferior Vena Cava: Cross Sectional Imaging Findings. Radio Graphics. 2000; vol. 20, no3, pp 639-640, 645, 651.

3. Phillips E. Embryology, normal anatomy and anomalies. In: Ferris EJ, Hipona FA, Kahn PC, Phillips E, Shapiro JH, eds. Venography of the inferior vena cava and its branches. Baltimore, Md: Williams \& Wilkins. 1969; 1-32.

4. Stardring S .Kidney and ureter In: Gray's Anatomy. 40th Ed. Churchill Livingstone Elsevier. 2008: 1233

5. Sadler T.W. Cardiovascular system In. Langman's Medical Embryology $10^{\text {th }}$ Edn , Lippincott Williams \& Wilkins ; 2006:188

6. Datta A.K. Circulatory system In : Essentials of human Embryology , $6^{\text {th }}$ Ed , Current Books International; $2010 ; 191-194$ 
7. Singh I.B. Urogenital system In: Human Embryology, $8^{\text {th }}$ Ed Macmillan India Limited 2008; 256-258.

8. Huntingdon GS, Mc Clure CFW. The development of veins in domestic cats (Felis domestica). Anat. Record. 1920; 20: 1.

9. Baldridge ED, Canos AJ. Venous anomalies encountered in aorto iliac surgery. Arch Surg. 1987; 122: 1184-8

10. Satyapal KS , Kalideen JM, Haffejee AA, Singh B, Robbs JV. Left renal vein variations surg Radiol Anat. 1999; 21: 77-81.

11. Davis, C.J. and Lundberg, G.D. Retroaortic left renal vein ,relatively frequent anomaly Am J. Clin .Path 1968,50,700-703

12. Reis ,R.H., and Esenther, G. Variations in pattern of renal vessels and their relation to type of posterior vena cava in man . Am J. Anat.1959,104,295-318

13. Brener BJ, Darling RC, Frederick PL, Linton RR. Major venous anomalies complicating abdomional aortic surgery In. Arch Surg. 1974; 108:n159-65.

14. Nonami Y, Yama Saki M, Aato K, SakaMoto H, Ogoshi S. Two types of major venous anomalies associated with abdominal aneurysmectomy : a report of two cases .Surgery Today Jpn J Surg. 1996 ; 26: 940-4

15. Toda R, Yoshifumi I, Moriyama Y, Hisashi M, Sakata R. Double Left Renal Vein Associated with abdominal aortic aneurysm. Ann Thorac Cardiovasc Surg. 2001; 7( 2): 113-115

16. Jafarpour M, Mofidpour H. Left renal vein variation: a cadaveric study. Med J Iran Hosp. July, 2002; 5: 25-27.

17. Hemalatha K, Narayani R, Murthy M, Korth MP, Jagadeesan K. Retro-aortic left renal vein and hypertension. Bombay Hospital J. 2008; 50: 6-9.

18. Sangeetha K, Srinivas Reddy K, Villo Rao M. Circumaortic renal collar - a case report. Journal of Andhra Pradesh State Anatomists. June 2010; vol 1.3: 17-20 


\section{CASE REPORT}

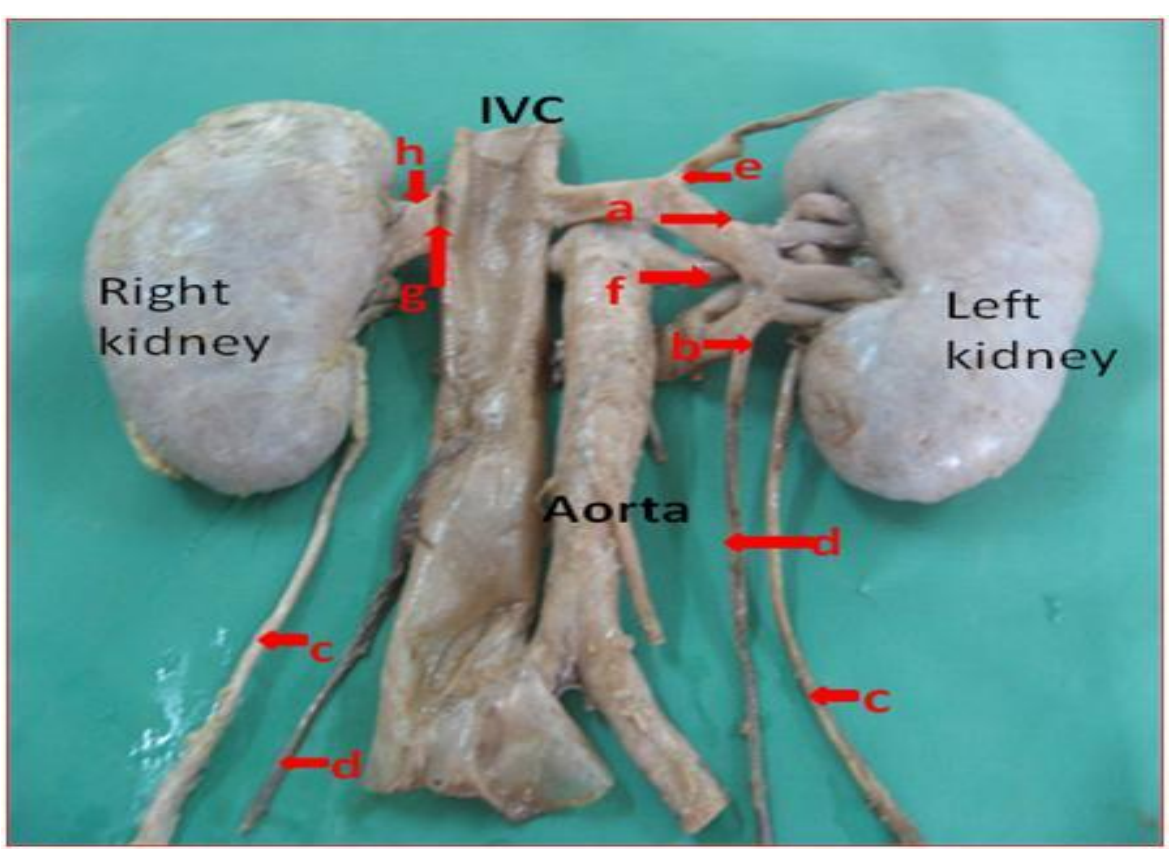

FIG 1: (Double left renal vein, Anterior view)

$a=$ Left pre aortic renal vein; $b=$ Left post aortic renal vein; $c=$ ureter; $d=$ gonadal vein; $\mathrm{e}=$ left suprarenal vein; $\mathrm{f}=$ left renal artery; $\mathrm{g}=$ right renal vein; $\mathrm{h}=$ right renal artery IVC= inferior vena cava.

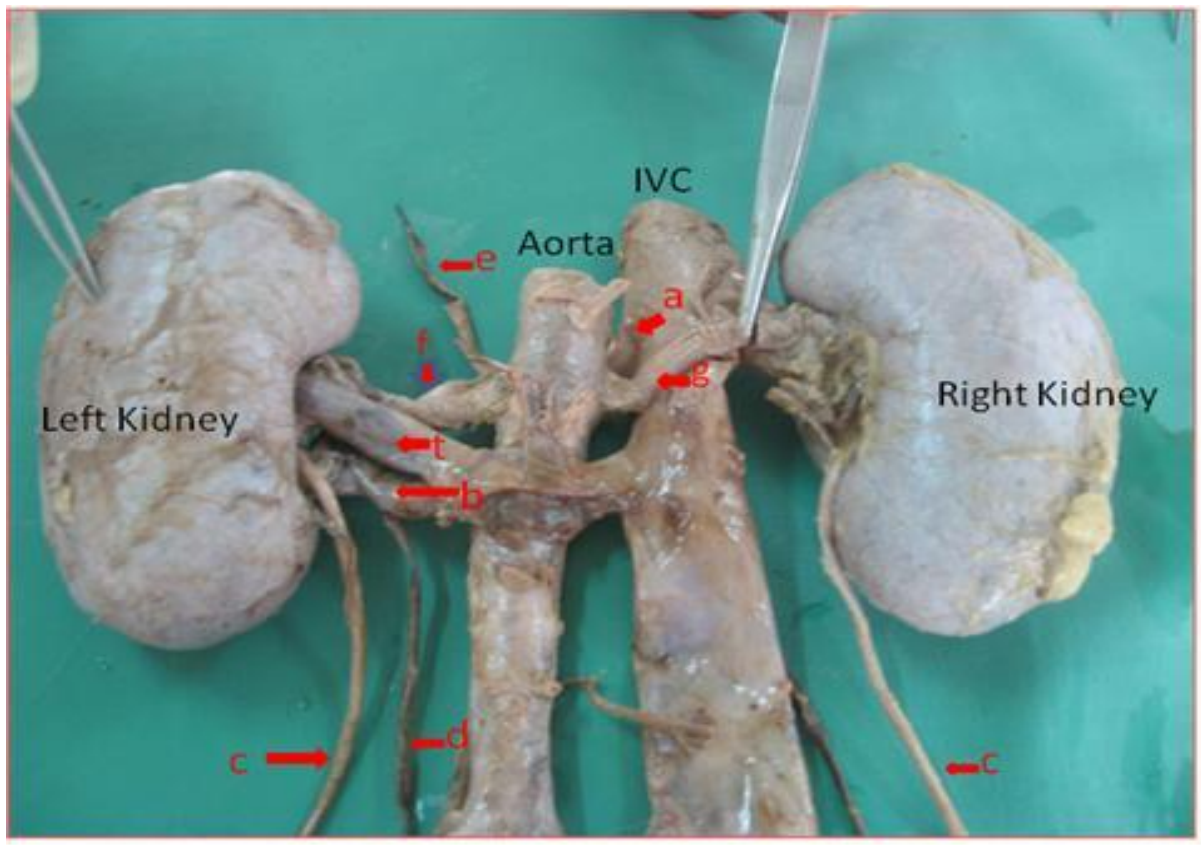

FIG 2: (Posterior view)

a - pre aortic left renal vein (partially hidden) b- post aortic left renal vein c- ureter

d- left gonadal vein

e- left suprarenal vein f- Left renal artery g- Right renal artey

t- tributary draining into -left renal vein. 


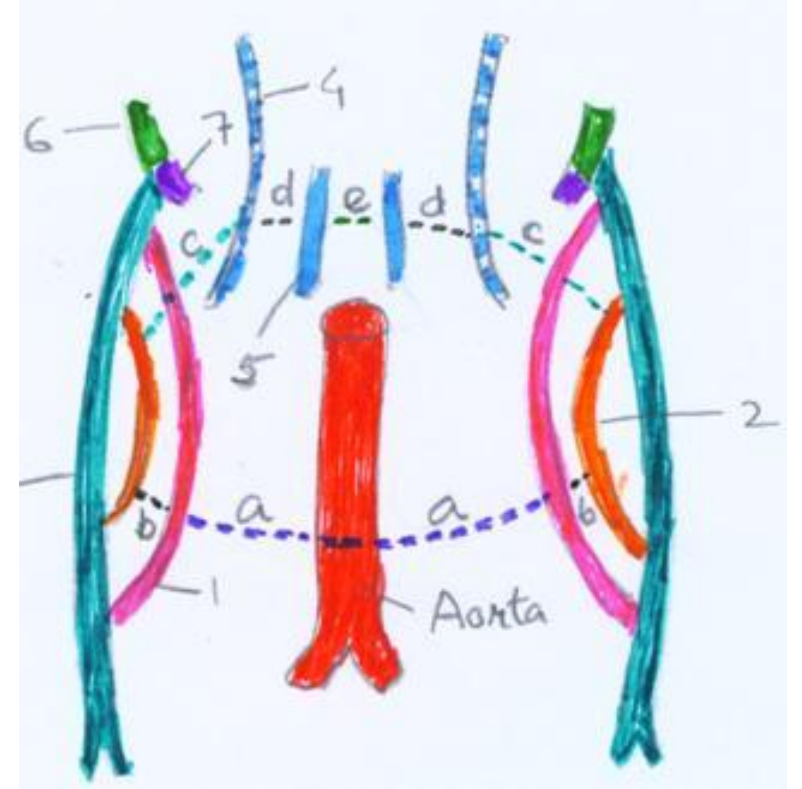

FIG 3: Anastomosis between venous channels

1- Subcardinal vein, 2- Supracardinal vein 3- Posterior cardinal vein 4- Azygos vein 5- Subcentral vein 6- Anterior cardinal vein

7 - Common cardinal vein

a- Anastomosis between subcardinal veins

b- Anastomosis between sub and supra cardinal vein

c- Anastomosis between supra and azygos vein

d- Anastomosis between azygos and subcentral vein

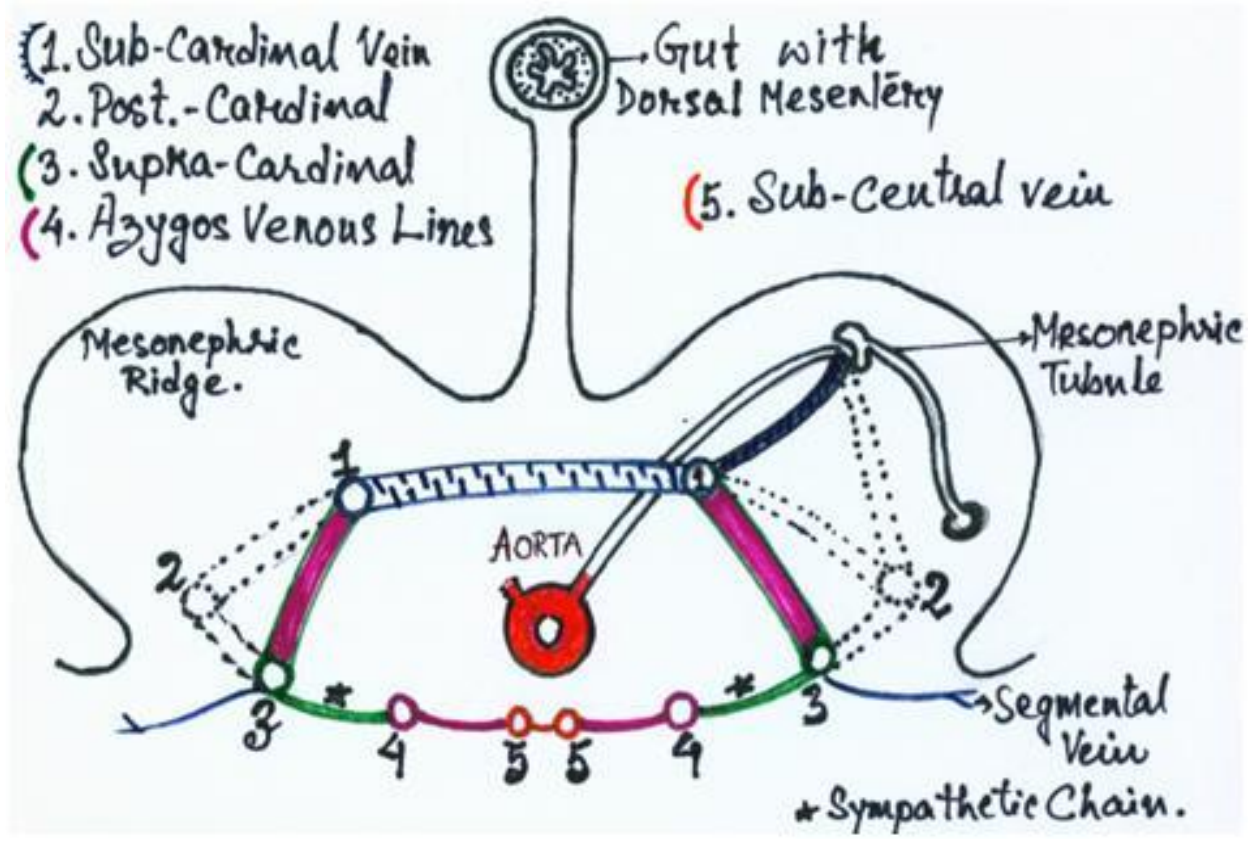

FIG 4: Veins of renal collar (cross section) 